\title{
Broken heart syndrome: tako-tsubo cardiomyopathy
}

\author{
Azeem Latib MD, Alfonso lelasi MD, Matteo Montorfano, Antonio Colombo MD
}

A 75-year-old hypertensive woman with a family history of coronary artery disease and infrequent episodes of paroxysmal atrial fibrillation was admitted with a 2-hour history of epigastric pain. An electrocardiogram showed evidence of atrial fibrillation with a rapid ventricular response (138 beats/min) and T-wave inversion inferolaterally (Figure 1A). The cardiac troponin I level was markedly elevated at 10.48 (normal $<0.07 \mu \mathrm{g} / \mathrm{L}$ ). The patient was given acetylsalicylic acid, clopidogrel, enoxaparin, amiodarone and irbesartan-hydrochlorothiazide. Pharmacologic cardioversion to sinus rhythm occurred within a few hours.

Coronary angiography for a suspected acute coronary syndrome did not show significant coronary artery disease. A left ventriculogram showed severe systolic dysfunction of the apical and middle segments, with preserved contraction of the basal segments (Figures 1B and 1C; video available at www .cmaj.ca/cgi/content/full/180/10/1033/DC1). Conservative treatment was begun, and follow-up echocardiography 2 days later showed improved apical contraction and normal left ventricular function. Based on a history of transient left ventricular dysfunction, electrocardiographic abnormalities and an absence of obstructive coronary artery disease, we diagnosed tako-tsubo cardiomyopathy.

\section{Discussion}

Tako-tsubo or stress cardiomyopathy (also known as apical ballooning syndrome) is a rare, reversible cardiomyopathy. ${ }^{1}$ Tako-tsubo is the Japanese word for an "octopus-trapping pot" that has a particular shape - a round bottom and narrow neck-resembling the left ventriculogram in systole in this syndrome. ${ }^{2}$ Tako-tsubo cardiomyopathy is characterized by transient left ventricular dysfunction, electrocardiographic abnormalities and minimal release of myocardial enzymes in $74 \%-86 \%$ of cases. ${ }^{3}$

Its most common clinical presentation includes dyspnea and chest pain mimicking an acute coronary syndrome but without obstructive coronary artery disease. ${ }^{1.3}$ Tako-tsubo cardiomyopathy may be associated with cardiac arrhythmias, in- cluding sinus bradycardia, atrioventricular block, atrial fibrillation and ventricular tachycardia or fibrillation. ${ }^{2}$

Although tako-tsubo cardiomypathy is a recognized differential diagnosis of acute coronary syndromes, the cardiac troponin I levels in our patient were markedly higher than those previously reported (mean troponin I $0.18 \mu \mathrm{g} / \mathrm{L}$, interquartile range $0.08-0.69 \mu \mathrm{g} / \mathrm{L} ;$ normal $<0.06 \mu \mathrm{g} / \mathrm{L}){ }^{4}$ Atrial fibrillation

\section{Key points}

- Tako-tsubo cardiomyopathy should be considered in patients who have evidence of acute coronary syndrome but normal coronary arteries on angiography.

- Left ventriculography is useful to show the classic findings of left ventricular apical ballooning and hypercontractile basal segments.

- In two-thirds of patients, the syndrome is associated with severe emotional or physical stress.

- Most patients will spontaneously recover left ventricular function by 3 months.

may occur in $6 \%-7 \%$ of cases; whether this is a precipitant or effect of the catecholamine excess and left ventricular dysfunction is not known. ${ }^{2}$

\section{Risk factors}

Postmenopausal women appear to be at higher risk of the condition than men. Because of its association with emotional or psychological stressors, such as the death of a loved one, takotsubo cardiomypathy has also been called the broken heart syndrome. ${ }^{4,5}$ Other known precipitants include acute intracranial events (bleeding, trauma or ischemic stroke), acute medical illness, surgical procedures, overproduction of endogenous cathecholamines and administration of exogenous cathecholaminergic agents. ${ }^{5}$ In about one-third of patients, no preceding emotional or physical stressor is identified. ${ }^{3}$

Although the precise pathogenesis is unknown, the following mechanisms have been suggested: enhanced sympathoneural activity, cathecholamine-mediated multivessel epicardial spasm, coronary microvascular dysfunction, and a possible direct cathecholamine-mediated myocyte injury and myocardial stunning. ${ }^{4,5}$

\section{Prognosis}

The prognosis is usually good. About one-third of patients recover left ventricular systolic function spontaneously by the time of hospital discharge (1 week). The remainder recover it over the ensuing 1-3 months. The average time to recovery is about 2-3 weeks. ${ }^{5,6}$ The risk of recurrence ranges from $2 \%-10 \%$, and the long-term prognosis is usually excellent for patients who survive the initial cardiac event. ${ }^{3,5}$

From the Interventional Cardiology Unit (Latib, Ielasi, Montorfano Colombo), San Raffaele Scientific Institute, and the Interventional Cardiology Unit (Colombo), EMO-GVM Centro Cuore Columbus, Milan, Italy 


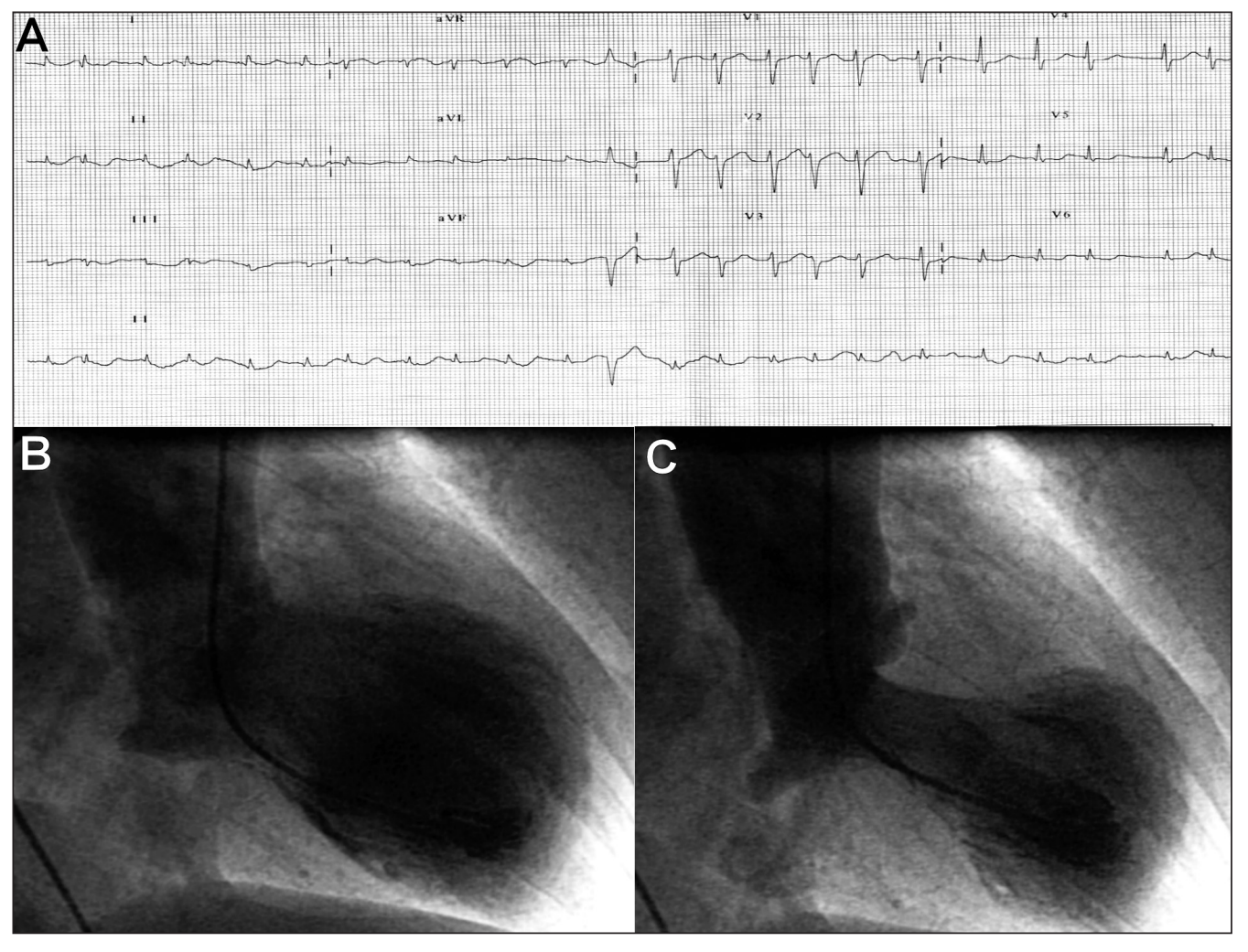

Figure 1: Panel A: Electrocardiogram showing atrial fibrillation with a rapid ventricular response, slight depression of the ST-segment in leads III and AVF, and T-wave inversion in leads I, II, III, AVF, AVL and V3-6. Panel B: Left ventriculogram in diastole. Panel C: End-systolic left ventriculogram demonstrating the classic apical ballooning and hypercontractile basal segments in the left ventricle (video available at www.cmaj.ca/cgi/content/full/180/10/1033/DC1.)

Patients with persistent left ventricular dysfunction at discharge should be prescribed a diuretic and an angiotensinconverting enzyme inhibitor or angiotensin-receptor blocker until left ventricular function returns to normal..$^{5}$ In addition, because sympathetic activation is presumed to be pivotal in the pathogenesis, long-term therapy with $\beta$-blockers that also have $\alpha$-adrenergic blocking properties (e.g., carvedilol) should be initiated with the aim of preventing recurrences. ${ }^{5}$ However, data are lacking to support these recommendations. Finally, repeat echocardiography should be performed before hospital discharge and after 1-3 months in patients with persistent left ventricular dysfunction.

This case highlights the importance of performing left ventriculography in patients who present with electrocardiographic and cardiac biomarker evidence of acute coronary syndrome but who have normal coronary arteries on angiography.

This article has been peer reviewed.

Competing interests: None declared.

\section{REFERENCES}

1. Dote K, Sato H, Tateishi H, et al. Myocardial stunning due to simultaneous multivessel coronary spasms: a review of 5 cases [Japanese]. J Cardiol 1991;21:203-14.

2. Tsuchihashi K, Ueshima K, Uchida T, et al. Transient left ventricular apical ballooning without coronary artery stenosis: a novel heart syndrome mimicking acute myocardial infarction. Angina pectoris-myocardial infarction investigations in Japan. J Am Coll Cardiol 2001;38:11-8.

3. Gianni M, Dentali F, Grandi AM, et al. Apical ballooning syndrome or takotsubo cardiomyopathy: a systematic review. Eur Heart J 2006;27:1523-9.

4. Wittstein IS, Thiemann DR, Lima JA, et al. Neurohumoral features of myocardial stunning due to sudden emotional stress. N Engl J Med 2005;352:539-48.

5. Bybee KA, Prasad A. Stress-related cardiomyopathy syndromes. Circulation 2008;118:397-409.

6. Sharkey SW, Lesser JR, Zenovich AG, et al. Acute and reversible cardiomyopathy provoked by stress in women from the United States. Circulation 2005;111:472-9.

Correspondence to: Dr. Antonio Colombo, EMO-GVM Centro Cuore Columbus, 48 Via M. Buonarroti, 20145 Milan, Italy; fax 3902 48193433; info@emocolumbus.it

The section Cases presents brief case reports that convey clear, practical lessons. Preference is given to common presentations of important rare conditions, and important unusual presentations of common problems. Articles start with a brief summary (100 words) outlining the case and its relevance to a general audience. The case presentation follows (500 words maximum) as well as a discussion of the underlying condition (1000 words maximum). Generally, up to 5 references are permitted and visual elements (e.g., tables of the differential diagnosis, clinical features or diagnostic approach) are encouraged. Written consent from patients for publication of their story is a necessity and should accompany submissions. See information for authors at www.cmaj.ca. 